\title{
Functional convergence of thalamic and intrinsic projections to cortical layers 4 and 6
}

\author{
Charles C. Lee and Kazuo Imaizumi \\ Department of Comparative Biomedical Sciences, LSU School of Veterinary Medicine, Baton \\ Rouge, LA 70803
}

\begin{abstract}
Ascending sensory information is conveyed from the thalamus to layers 4 and 6 of sensory cortical areas. Interestingly, receptive field properties of cortical layer 6 neurons are different from those in layer 4. Do such differences reflect distinct inheritance patterns from the thalamus or are they derived instead from local cortical circuits? To distinguish between these possibilities, we utilized in vitro slice preparations containing the thalamocortical pathways in the auditory and somatosensory systems. Responses from neurons in layers 4 and 6 that resided in the same column were recorded using whole-cell patch clamp. Laser-scanning photostimulation via uncaging of glutamate in the thalamus and cortex was used to map the functional topography of thalamocortical and intracortical inputs to each layer. In addition, we assessed the functional divergence of thalamocortical inputs by optical imaging of flavoprotein autofluorescence. We found that the thalamocortical inputs to layers 4 and 6 originated from the same thalamic domain, but the intracortical projections to the same neurons differed dramatically. Our results suggest that the intracortical projections, rather than the thalamic inputs, to each layer contribute more to the differences in their receptive field properties.
\end{abstract}

\section{Introduction}

In the sensory forebrain, thalamocortical axons branch and synapse in layers 4 and 6 of their target cortical areas [1-4]. These branched projections enable ascending sensory information to be conveyed directly and in parallel to each cortical layer. Supporting such parallel streams, the short-term synaptic plasticity of thalamocortical inputs to both layers 4 and 6 are similar, exhibiting depressing postsynaptic responses to repetitive electrical stimulation [5-9], and are similar to those observed at other synapses in the sensory forebrain [10-12].

Interestingly, despite the direct nature of the thalamocortical inputs to these layers, receptive field properties in layer 6 are distinct from those in layer 4 [13-18]. For example, in the auditory cortex, spectral and temporal modulation preferences differ between layers, with layer 6 responding to broader spectral and lower temporal modulations compared to layer 4 [14]. Tuning preferences likewise vary among layers in the visual $[13,16]$ and somatosensory $[15,17]$ cortices. This arrangement poses a dilemma and it therefore remains an open question whether such differences in receptive field properties among layers reflect distinct inheritance patterns from the thalamus, or are derived instead from local cortical circuits or another mechanism.

Indeed, all layers of the cortex receive convergent input from a wide constellation of intrinsic cortical sources, which comprise over half of the total number of convergent inputs

Correspondence to: Charles C. Lee, Department of Comparative Biomedical Sciences, LSU School of Veterinary Medicine, Skip Bertman Drive, Baton Rouge, LA 70803, cclee@1su.edu, Telephone: (225) 578-9032, Fax: (225) 578-9895. 
from combined thalamic and cortical sources [19-21]. Intrinsic synapses outnumber those arising from thalamic sources. In the visual cortex, for example, thalamic synapses comprise only five percent of the total innervation on layer 4 thalamorecipient neurons [22, 23]. Thus, the intricate and prolific connections from local cortical circuits are potentially poised to refine and modulate the information arriving through the ascending thalamocortical streams $[12,24-26]$.

Therefore, to explore the relative contributions of thalamic and intracortical projections to layers 4 and 6, we utilized in vitro slice preparations containing the intact thalamocortical pathways in the auditory and somatosensory systems. Responses from neurons in layers 4 and 6 that resided in the same column were recorded using whole-cell patch clamp. Laserscanning photostimulation via uncaging of glutamate in the thalamus and cortex was used to map the functional topography of thalamocortical and intracortical inputs. In addition, optical imaging of flavoprotein autofluorescence in the cortex in response to thalamic stimulation was used to assess the spatial and temporal pattern of activity in layers 4 and 6 following thalamic stimulation.

\section{Materials and Methods}

\subsection{Slice preparation}

Thalamocortical slices were prepared from BALB/c mice (ages p11-p18). The Institutional Animal Care and Use Committee of the Louisiana State University School of Veterinary Medicine approved all procedures. Animals were first deeply anesthetized by isofluorane, as assessed by cessation of withdrawal reflexes to strong toe-pinches. Following decapitation, the brains were quickly dissected then submerged in cool, oxygenated, artificial cerebral spinal fluid (ACSF; in mM: $125 \mathrm{NaCl}, 25 \mathrm{NaHCO}_{3}, 3 \mathrm{KCl}, 1.25 \mathrm{NaH}_{2} \mathrm{PO}_{4}, 1 \mathrm{MgCl}_{2}, 2$ $\mathrm{CaCl}_{2}, 25$ glucose). Brains were then blocked to preserve the thalamocortical projections to either the primary auditory cortex (A1) [27] or primary somatosensory cortex (S1) [28]. The blocked brains were affixed to a stage with instant glue adhesive and then $500 \mu \mathrm{m}$ thick sections were collected in cold, oxygenated ACSF using a vibratome (World Precision Instruments, Sarasota, FL). Collected slices were transferred to a holding chamber for $1 \mathrm{~h}$ at $32^{\circ} \mathrm{c}$ in ACSF and then moved to a recording chamber perfused with ACSF at $32^{\circ} \mathrm{c}$ on a modified microscope stage (Siskiyou, Grants Pass, OR).

\subsection{Recording, photostimulation, and optical imaging}

Neurons were visualized under DIC optics on an Olympus BX-51 upright microscope equipped with a U-DPMC intermediate magnification changer with $0.25 \times$ and $4 \times$ intermediate lenses (Olympus America, Center Valley, PA), rear-mounted with a Hitachi KP-M1AN camera (Hitachi, Tarrytown, NY) and front-mounted with a Retiga-EX camera (QImaging, Surrey, Canada). Whole-cell voltage clamp recordings were made using the Multiclamp 700B amplifier and pCLAMP software (Molecular Devices, Sunnyvale, CA) or Ephus software (Janelia Farms, Ashburn, VA). Recordings were performed in voltage clamp using a potassium intracellular solution (in mM: $135 \mathrm{~K}$-gluconate, $7 \mathrm{NaCl}, 10 \mathrm{HEPES}, 1-2$ $\mathrm{Na}_{2}$ ATP, $0.3 \mathrm{GTP}, 2 \mathrm{MgCl}_{2}$, pH 7.3, $290 \mathrm{mOsm}$ ). Cytoarchitectural and anatomical markers determined laminar positions of neurons, as we have previously demonstrated [9, 24, 25]. The lower border of layer 4 was apparent by the transition from small, densely packed neurons to larger, more sparsely packed neurons in layer $5[29,30]$. In the somatosensory slice, layer 4 was readily identifiable by the canonical barrel and septal regions $[9,28]$. Similarly, the borders of layer 6 were determined by the white matter and the transition to the large, sparsely packed neurons in layer $5[9,24,25]$. Depolarizing current injections were used to determine the spiking characteristics of the recorded neurons. Regular spiking (RS) neurons were classified as firing at slow adapting frequencies $(<30 \mathrm{~Hz})$ with small and 
slow afterhyperpolarizations (AHPs; 5-10 mV), while fast-spiking (FS) neurons were classified according to higher maximal firing rates $(>30 \mathrm{~Hz})$, with large and fast AHPs $(10$ $15 \mathrm{mV}$ ). The acquired data were recorded and digitized using a Digidata 1440A acquisition board (Molecular Devices) or a National Instruments BNC 2090 terminal block (National Instruments, Austin, TX), and then stored in a computer for later analysis.

Laser-scanning photostimulation (LSPS) with caged glutamate was used to map the thalamic and cortical regions eliciting EPSCs in the recorded layer 4 or 6 neurons of interest $[9,25$, 31]. After patching, a recirculating ACSF bath containing nitroindolinyl (NI)-caged glutamate $(0.37 \mathrm{mM}$; Sigma-RBI) was switched in place of the regular ACSF bath. Direct responses to photostimulation were determined by using a solution containing caged glutamate in a low $\mathrm{Ca}^{2+}(0.2 \mathrm{mM}) / \mathrm{high}^{2+}(6 \mathrm{mM})$ ACSF solution with TTX $(1 \mu \mathrm{M})$ and synaptic responses estimated by subtraction. Photolysis of the caged glutamate was done focally with a pulsed UV laser (DPSS Lasers, Inc., Santa Clara, CA, USA). Custom software (Ephus) written in MATLAB (MathWorks, Inc., Natick, MA, USA) was used to control the galvanometer mirror positioning of the laser beam for photostimulation and to analyze the data [32]. We used a $16 \times 16$ stimulation array with $80 \mu \mathrm{m}$ spacing between adjacent rows and columns. Previous controls demonstrated that laser uncaging of glutamate elicits action-potential within $\sim 40-50 \mu \mathrm{m}$ of the soma [25, 33]. The mean EPSCs elicited from three map repetitions were averaged and the interpolated plots superimposed on photomicrographs corresponding to the stimulation sites. Thalamic and laminar boundaries were determined from cytoarchitectural landmarks in the DIC images [9, 33]. The ventrobasal (VB) nucleus is discerned as a dark, crescent shaped structure with fibers traversing it laterally $[9,28]$. The medial geniculate body (MGB) is visualized as an almondshaped structure that is lighter in brightness than the laminated structure of the lateral geniculate nucleus (LGN) rostrally and the darker appearance of the ventrobasal complex medially $[9,27,33]$. The thalamic region projecting to a given recorded layer 6 neuron was measured from the thalamic photostimulation sites that elicited EPSCs and normalizing to the region eliciting EPSCs of the recorded layer 4 neuron in the same column. The averaged mean EPSCs were totaled from each stimulation site in both the thalamus and cortex for a given neuron to determine the percent contribution from each thalamic and intracortical source. Statistical comparisons of distributions were performed using StatPlus (AnalystSoft, Vancouver, BC).

Metabolic activity in response to thalamic stimulation was measured with the front-mounted Retiga-EX camera (QImaging) by capturing green light $(\sim 510-540 \mathrm{~nm})$ generated by mitochondrial flavoproteins in the presence of blue light $(\sim 450-490 \mathrm{~nm})$ [34]. Optical images were captured over $12 \mathrm{sec}$ runs using Streampix 5.13 (Norpix Inc., Montreal, Quebec, Canada) following electrical stimulation in the thalamic regions projecting to the cortical areas being imaged. Electrical stimulation was performed using a concentric bipolar electrode (WPI, Sarasota, FL) to deliver a repetitive stimulation train of $100 \mathrm{~Hz}$ lasting for $500 \mathrm{~ms}$ controlled by a Master-9 pulse generator (A.M.P.I., Jerusalem, Israel) at stimulation intensities of 50-200 $\mu \mathrm{A}$ adjusted using an A365R stimulus isolator (World Precision Instruments, Sarasota, FL). Image exposure time ranged from 80 to $150 \mathrm{~ms}$. Images were taken at $4 \times$ magnification and processed using custom software written to run on Matlab $[34,35]$. Spatial and temporal signal profiles were analyzed using ImageJ $(\mathrm{NIH}$, Bethesda, MD). Defined regions of interest (ROIs) were used to measure the change in pixel intensity within or across cortical layers. For temporal analyses, ROIs in the center of maximal activation in layers 4 or 6 in the same column were chosen and the change in intensity across image stacks (time) was plotted for each layer. 


\subsection{In vitro tract-tracing}

Following physiological recordings, selected slices were transferred for post-fixation to a 4\% paraformaldehyde solution (Electron Microscopy Sciences, Hatfield, PA) in $10 \mathrm{mM}$ phosphate buffered saline (pH 7.3). DiI crystals (Life Technologies, Grand Island, NY) were carefully placed with a needle in the thalamic nuclei (VB or MGB) of thalamocortical slices under a dissecting microscope (AmScope, Irvine, CA). Slices were covered with aluminum foil and incubated in the dark at room temperature for 2-3 months. Following adequate lipophilic diffusion of DiI into thalamocortical fibers, slices were mounted between two pieces of coverglass with Vectashield hard set mounting medium (Vector Labs, Burlingame, CA). DiI labeled fibers were then visualized using a Leica TCS SP2 confocal laser-scanning microscope (Leica Microsystems, Buffalo Grove, IL) housed in the microscopy center at the LSU School of Veterinary Medicine. Acquired images were analyzed using ImageJ (NIH).

\section{Results}

In order to assess the connectivity of the thalamocortical slice preparations, DiI crystals were placed into the respective thalamic nuclei in the auditory and somatosensory slices (Figs. 1, 2). In the auditory slice preparation (Fig. 1), thalamocortical fibers originated in the medial geniculate body (MGB) and traversed rostrally towards the thalamic reticular nucleus (TRN) (Fig. 1A), where they ramified profusely before continuing laterally towards the cerebral cortex (Fig. 1B). As these fibers approached the primary auditory cortex (A1), they rerouted caudally before entering the deep cortical layers (Fig. 1B, C). Upon entering the deep layers, fibers branched in layer 6 before continuing towards the upper cortical layers (Fig. 1D). This pattern was similar, but somewhat more continuous, to that described previously [27]. In the somatosensory slice preparation (Fig. 2), thalamocortical fibers traversed laterally from the ventrobasal complex to the TRN before curving dorsally towards the primary somatosensory cortex (S1) (Fig. 2A, B), where they formed a distinct band in layers 4 and 6 of S1 (Fig. 2C, D). In both the auditory and somatosensory slices, retrogradely labeled cell bodies were observed in layer 6 (Fig 1C, 2C), indicative of the robust feedback projections from the cortex to the thalamus [36-38].

To further characterize the thalamocortical projections in these slice preparations, we utilized optical imaging of flavoprotein autofluorescence (FA) in the cortex following electrical stimulation of the thalamus (Figs. 3, 4). We found robust FA activation in the primary auditory and somatosensory cortices, which peaked approximately $1 \mathrm{sec}$ following thalamic stimulation and at the same time in both layers 4 and 6 (Figs. 3D, 4D). At the time of maximal activation, in the auditory cortex $(n=3)$, robust autofluorescence was especially visible in layers 3 and 4, with weaker activation in lower layers, including layer 6 (Fig. 3A,B). Despite the difference in the intensity among layers 4 and 6 (Fig. 3B), the areal extent of the activation was similar for both layers 4 and 6, originating at similar rostralcaudal extremes and cresting at the same rostral-caudal location (Fig. 3A,C). In the primary somatosensory cortex $(n=3)$, autofluorescence was most prevalent in the barrel regions of layer 4 and decreased in the upper and lower cortical layers (Fig. 4A,B). The barrel architecture resulted in a periodic areal pattern of activation across $\mathrm{S} 1$ in layer 4 , which was not evident in layer 6 (Fig. 4A,C).

We further sought to compare the functional convergence of inputs to pairs of neurons in layers 4 and 6 in the auditory and somatosensory system using whole-cell patch clamp recordings of cortical neurons in response to laser-scanning photostimulation (LSPS) via uncaging of glutamate (Figs. 5, 6) [9, 24, 25, 33]. In each slice preparation, we recorded from regular-spiking (RS) neurons in layers 4 and 6 (A1: $n=6$ pairs; $S 1: n=10$ pairs) residing along a presumptive cortical column, as determined by cytoarchitectural and anatomical boundaries. We then mapped the topography of LSPS-evoked EPSCs in the thalamic and 
cortical areas projecting to the recorded neuron. In both the auditory (Fig. 5) and somatosensory (Fig. 6) slices, we found that the areal extent and location of the thalamus that elicited EPSCs in layer 4 (Figs. 5A, 6A) and layer 6 (Figs. 5B, 6B) neurons were similar (Figs. 5E, 6E) (Layer 6 to 4 ratio; A1: $99 \pm 43 \%$; S1: $108 \pm 31 \%$; Combined: $103 \pm 35 \%$ ). But, the mean evoked currents to layer 6 were weaker than those to layer 4 (Figs. 5E, 6E) (Layer 6 to 4 ratio; A1: $86 \pm 24 \%$; S1: $89 \pm 19 \%$; Combined: $88 \pm 21 \%$ ).

The similar functional topography of the thalamic inputs contrasted with different input patterns from intracortical laminar sources to layers 4 and 6. In general, layer 4 neurons received the bulk of total evoked current from layer 3 (A1: $29.2 \pm 4.6 \%$; S1: $25.0 \pm 6.5 \%$; Combined: $26.5 \pm 5.9 \%$ ) and layer $4(\mathrm{~A} 1: 33.3 \pm 2.9 \%$; S1: $42.4 \pm 11.5 \%$; Combined: $39.0 \pm$ $10.0 \%$ ) (Figs. 5C, F; 6C, F; Table 1). In comparison, layer 6 received the bulk of evoked current from layer 5 (A1: $29.2 \pm 7.3 \%, \mathrm{~S} 1: 31.8 \pm 3.1 \%$, Combined: $30.8 \pm 4.8 \%$ ) and layer 6 (A1: $44.5 \pm 2.1 \%$, S1: $46.9 \pm 7.2 \%$, Combined: $46.0 \pm 5.8 \%$ ) (Figs. 5D, F; 6D, F; Table 1). The proportion of evoked currents from these laminar sources to neurons in layers 4 and 6 were statistically different ( $t$-test, $\mathrm{p}<0.01$; Table 1 ). In comparison with the thalamic evoked currents, intracortical sources provided approximately $90 \%$ of the total evoked current, while thalamic sources contributed less than $10 \%$ (Figs. 5F, 6F, 7; Table 1).

\section{Discussion}

Ascending thalamocortical axons innervate layers 4 and 6 of the primary auditory and somatosensory cortices [1-4]. Using laser-scanning photostimulation via uncaging of glutamate to map the functional convergence of thalamocortical (TC) inputs, we found that neurons in layers 4 and 6 in a cortical column receive functional input from the same thalamic region. In our experiments, we recorded primarily from young animals whose synaptic properties and connectivity may be undergoing rapid changes [39-41]. Although the relative proportion and spatial distribution of excitatory inputs were similar for all animals in our study, we did not directly assess convergence from intracortical inhibitory sources $[42,43]$, which may be still developing at this point $[39,41]$.

Our results are consistent with previous studies of the functional topography of the thalamocortical pathways [9, 44, 45]. In their study, Bureau et al. (2006) found that the thalamic inputs from lemniscal and paralemniscal nuclei (VPm and POm) to the somatosensory cortex were interdigitated, such that POm projected primarily to layer 5a, while VPm projections to layers 4, 5b and 6 overlapped for pairs in the same column. Here, we found a similar alignment of thalamic projections to layer 4 and 6 neurons in the somatosensory barrel cortex [46], which we also observed in the auditory thalamocortical projections to layers 4 and 6 of A1. This suggests that a similar topographic principle organizes the TC projections in both systems, which perhaps extends to other modalities, such as the visual system [8].

This pattern of functional convergence revealed by LSPS mapping of thalamocortical projections is supported by the pattern of divergence revealed by optical imaging methods $[34,35,47-57]$. Although we observed that electrical stimulation of the thalamus resulted in similar temporal patterns of activation in these layers of the auditory and somatosensory cortices, similar to previous studies [48, 49, 51-54], the autofluorescence imaging method that we employed does not enable the fine temporal discrimination available with voltagesensitive dyes, which has revealed possible laminar latency differences in the auditory cortex [55]. Ours and other previous studies have observed robust flavoprotein activation in layers 4 and 6 of the auditory and somatosensory cortices following thalamic electrical and photostimulation, but typically with more prominent activity in layer $6[35,47]$. Our finding of relatively weaker activity in layer 6 matches more closely that observed by Broicher et al. 
(2010), who used voltage sensitive dyes, and attributed laminar intensity differences in A1 to the interaction of intracortical circuits. Our findings may result from similar intrinsic mechanisms or methodological ones, such as the intensity of stimulation and perhaps less antidromic activation of layer 6 corticothalamic neurons. Still, the spatial distribution of activity in layers 4 and 6 observed in this and previous studies suggest that feedforward and feedback projections are likely topographically aligned.

Despite the similar functional topography of the thalamic inputs, the intracortical inputs to layers 4 and 6 differed. We found that layer 4 received predominant inputs from layers 3 and 4 , while layer 6 received predominant inputs from layers 5 and 6 , which are similar to the distributions observed in prior studies [24, 45, 58-63]. In general, local connectivity within a layer tends to predominate for each layer [60], although area specific differences in local circuits exist, such as the respective parallel layer 4 and 5a projections to layers 2 and 3 in the barrel and septal regions of $S 1[64,65]$ and the asymmetric layer 6 projections to layer 3 in A1 [45]. These functional patterns of connectivity align with the morphological distributions of local circuit axons observed in layers 4 and 6 of cat A1 [30, 66-71]. As such, the laminar differences in local circuit connectivity provide a morphological basis for the differences in receptive field properties observed between layers 4 and 6 [13-18]. In this respect, while the same basic features of the receptive field are inherited from thalamic sources [72,73], the subsequent and ongoing recruitment of local intracortical sources likely sculpt responsive refinements, e.g. the observed temporal and modulation preferences in layers 4 and 6 of A1 [14].

Finally, we found that the thalamocortical projections account for approximately $10 \%$ of the total evoked current in both layers from thalamic and intracortical sources. Interestingly, these values are similar in magnitude to the anatomical estimates of the proportion of thalamic and intracortical synapses in layer $4[22,23]$ and the proportion of thalamic neurons converging across layers $[20,74]$. This suggests a relative equivalence in the efficacy of thalamic with intracortical projections, which anatomically contribute nearly half of the total convergent input to an area [19-23, 75] and is consistent with the notion of synchronous convergent thalamic synapses that are weak individually [76]. This arrangement may also be necessary for the fewer thalamic inputs to activate the more numerous intracortical projections, which may amplify and process the ascending signal [52, 77-80], resulting in the observed differences in laminar receptive field properties among layers. The thalamocortical recruitment of intracortical circuits, both excitatory and inhibitory, may also account for differences in cortical dynamic responses to transient and sustained activity [81]. Thus, the functional circuitry of the sensory forebrain is comprised of convergent thalamocortical pathways that lead to computationally divergent outcomes emerging from concurrent intracortical projections.

\section{Acknowledgments}

We thank Ben Suter and Brian Theyel for their assistance with custom analysis software, Xiaochu Wu for assistance with confocal microscopy, and Pooja Venkatadri and Courtney Burgess for technical assistance. This work was supported by NIH/NIDCD grant R03 DC 11361, SVM USDA CORP grant LAV3202, NSF-LA EPSCoR grant PFUND276, and Louisiana Board of Regents RCS grant RD-A-09.

\section{References}

1. Huang CL, Winer JA. Auditory thalamocortical projections in the cat: laminar and areal patterns of input. J Comp Neurol. 2000; 427:302-331. [PubMed: 11054695]

2. Smith PH, Uhlrich DJ, Manning KA, Banks MI. Thalamocortical projections to rat auditory cortex from the ventral and dorsal divisions of the medial geniculate nucleus. J Comp Neurol. 2012; 520:34-51. [PubMed: 21618239] 
3. Landry P, Deschênes M. Intracortical arborizations and receptive fields of identified ventrobasal thalamocortical afferents to the primary somatic sensory cortex in the cat. J Comp Neurol. 1981; 199:345-372. [PubMed: 7263953]

4. Humphrey AL, Sur M, Ulrich DJ, Sherman SM. Termination patterns of individual X- and Y-cell axons in the visual cortex of the cat: projections to area 18, to the $17 / 18$ border region, and to both areas 17 and 18. J Comp Neurol. 1985; 233:190-212. [PubMed: 3973101]

5. Beierlein M, Connors BW. Short-term dynamics of thalamocortical and intracortical synapses onto layer 6 neurons in neocortex. J Neurophysiol. 2002; 88:1924-1932. [PubMed: 12364518]

6. Rose HJ, Metherate R. Auditory thalamocortical transmission is reliable and temporally precise. J Neurophysiol. 2005; 94:2019-2030. [PubMed: 15928054]

7. Stratford KJ, Tarczy-Hornoch K, Martin KA, et al. Excitatory synaptic inputs to spiny stellate cells in cat visual cortex. Nature. 1996; 382:258-261. [PubMed: 8717041]

8. MacLean JN, Fenstermaker V, Watson BO, Yuste R. A visual thalamocortical slice. Nat Methods. 2006; 3:129-134. [PubMed: 16432523]

9. Lee CC, Sherman SM. Synaptic properties of thalamic and intracortical intputs to layer 4 of the first- and higher-order cortical areas in the auditory and somatosensory systems. J Neurophysiol. 2008; 100:317-326. [PubMed: 18436628]

10. Sherman SM, Guillery RW. On the actions that one nerve cell can have on another: distinguishing "drivers" from "modulators". Proc Natl Acad Sci U S A. 1998; 95:7121-7126. [PubMed: 9618549]

11. Lee CC, Sherman SM. On the classification of pathways in the auditory midbrain, thalamus, and cortex. Hear Res. 2011; 276:79-87. [PubMed: 21184817]

12. Lee CC, Sherman SM. Drivers and modulators in the central auditory pathways. Front Neurosci. 2010; 4:79-86. [PubMed: 20589100]

13. Gilbert CD. Laminar differences in receptive field properties of cells in cat primary visual cortex. J Physiol. 1977; 268:391-421. [PubMed: 874916]

14. Atencio CA, Schreiner CE. Laminar diversity of dynamic sound processing in cat primary auditory cortex. J Neurophysiol. 2010; 103:192-205. [PubMed: 19864440]

15. Dykes RW, Lamour Y. An electrophysiological study of single somatosensory neurons in rat granular cortex serving the limbs: a laminar analysis. J Neurophysiol. 1988; 70:703-724. [PubMed: 3171648]

16. Martinez LM, Wang Q, Reid RC, et al. Receptive field structure varies with layer in the primary visual cortex. Nat Neurosci. 2005; 8:372-379. [PubMed: 15711543]

17. Brumberg JC, Pinto DJ, Simons DJ. Cortical columnar processing in the rat whisker-to-barrel system. J Neurophysiol. 1999; 82:1808-1817. [PubMed: 10515970]

18. Wallace MN, Palmer AR. Laminar differences in the response properties of cells in the primary auditory cortex. Exp Brain Res. 2008; 184:179-191. [PubMed: 17828392]

19. Lee CC, Winer JA. Connections of cat auditory cortex: III. Corticocortical system. J Comp Neurol. 2008; 507:1920-1943. [PubMed: 18271030]

20. Lee CC, Winer JA. Convergence of thalamic and cortical pathways in cat auditory cortex. Hear Res. 2011; 274:85-94. [PubMed: 20576491]

21. Lee, CC.; Winer, JA. A synthesis of auditory cortical connections: thalamocortical, commissural, and corticocortical systems. In: Winer, JA.; Schreiner, CE., editors. The auditory cortex. Springer; New York: 2011. p. 147-170.

22. Binzegger T, Douglas R, Martin K. A quantitative map of the circuit of cat primary visual cortex. J Neurosci. 2004; 24:8441-8453. [PubMed: 15456817]

23. Ahmed B, Anderson JC, Douglas RJ, et al. Polyneuronal innervation of spiny stellate neurons in cat visual cortex. J Comp Neurol. 1994; 341:39-49. [PubMed: 8006222]

24. Lee CC, Sherman SM. Modulator property of the intrinsic cortical projections from layer 6 to layer 4. Front Syst Neurosci. 2009; 3:3. [PubMed: 19277215]

25. Lee CC, Sherman SM. Intrinsic modulators of auditory thalamocortical transmission. Hear Res. 2012; 287:43-50. [PubMed: 22726616] 
26. Lee CC, Lam YW, Sherman SM. Intracortical convergence of layer 6 neurons. Neuroreport. 2012; 23:736-740. [PubMed: 22776905]

27. Cruikshank SJ, Rose HJ, Metherate R. Auditory thalamocortical synaptic transmission in vitro. J Neurophysiol. 2002; 87:361-384. [PubMed: 11784756]

28. Agmon A, Connors BW. Thalamocortical responses of mouse somatosensory (barrel) cortex in vitro. Neuroscience. 1991; 41:365-379. [PubMed: 1870696]

29. Winer JA, Lee CC. The distributed auditory cortex. Hear Res. 2007; 229:3-13. [PubMed: 17329049]

30. Winer JA, Prieto JJ. Layer V in cat primary auditory cortex (AI): cellular architecture and identification of projection neurons. J Comp Neurol. 2001; 434:379-412. [PubMed: 11343289]

31. Lee CC, Sherman SM. Glutamatergic inhibition in sensory neocortex. Cereb Cortex. 2009; 19:2281-2289. [PubMed: 19176638]

32. Suter BA, O'Connor T, Iyer V, et al. Ephus: multipurpose data acquisition software for neuroscience experiments. Front Neural Circuits. 2010; 4:100. [PubMed: 21960959]

33. Lee CC, Sherman SM. Topography and physiology of ascending streams in the auditory tectothalamic pathway. Proc Natl Acad Sci U S A. 2010; 107:372-377. [PubMed: 20018757]

34. Theyel BB, Llano DA, Issa NP, et al. In vitro imaging using laser photostimulation with flavoprotein autofluorescence. Nat Protoc. 2011; 6:502-508. [PubMed: 21455186]

35. Theyel BB, Lee CC, Sherman SM. Specific and nonspecific thalamocortical connectivity in the auditory and somatosensory thalamocortical slices. Neuroreport. 2010; 21:861-864. [PubMed: 20647961]

36. Llano DA, Sherman SM. Evidence for non-reciprocal organization of the mouse auditory thalamocortical-corticothalamic projections systems. J Comp Neurol. 2008; 507:1209-1227. [PubMed: 18181153]

37. Winer JA, Diehl JJ, Larue DT. Projections of auditory cortex to the medial geniculate body of the cat. J Comp Neurol. 2001; 430:27-55. [PubMed: 11135244]

38. Reichova I, Sherman SM. Somatosensory corticothalamic projections: distinguishing drivers from modulators. J Neurophysiol. 2004; 92:2185-2197. [PubMed: 15140908]

39. Sanes DH, Kotak VC. Developmental plasticity of auditory cortical inhibitory synapses. Hear Res. 2011; 279:140-148. [PubMed: 21463668]

40. Erzurumlu RS, Gaspar P. Development and critical period plasticity of the barrel cortex. Eur J Neurosci. 2012; 35:1540-1553. [PubMed: 22607000]

41. Oswald AM, Reyes AD. Development of inhibitory timescales in auditory cortex. Cereb Cortex. 2011; 21:1351-1361. [PubMed: 21068186]

42. Zhou Y, Liu BH, Wu GK, et al. Preceding inhibition silences layer 6 neurons in auditory cortex. Neuron. 2010; 65:706-717. [PubMed: 20223205]

43. Wehr M, Zador AM. Balanced inhibition underlies tuning and sharpens spike timing in auditory cortex. Nature. 2003; 426

44. Bureau I, von Saint Paul F, Svoboda K. Interdigitated paralemniscal and lemniscal pathways in the mouse barrel cortex. PLoS Biol. 2006; 4:e382. [PubMed: 17121453]

45. Oviedo HV, Bureau I, Svoboda K, Zador AM. The functional asymmetry of auditory cortex is reflected in the organization of local cortical circuits. Nat Neurosci. 2010; 13:1413-1420. [PubMed: 20953193]

46. Wimmer VC, Bruno RM, de Kock CP, et al. Dimensions of a projection column and architecture of VPM and POm axons in rat vibrissal cortex. Cereb Cortex. 2010; 20:2265-2276. [PubMed: 20453248]

47. Llano DA, Theyel BB, Mallik AK, et al. Rapid and sensitive mapping of long-range connections in vitro using flavoprotein autofluorescence imaging combined with laser photostimulation. $\mathrm{J}$ Neurophysiol. 2009; 101:3325-3340. [PubMed: 19321634]

48. Higashi S, Crair MC, Kurotani T, et al. Altered spatial patterns of functional thalamocortical connections in the barrel cortex after neonatal infraorbital nerve cut revealed by optical recording. Neuroscience. 1999; 91:439-452. [PubMed: 10366001] 
49. Laaris N, Carlson GC, Keller A. Thalamic-evoked synaptic interactions in barrel cortex revealed by optical imaging. J Neurosci. 2000; 20:1529-1537. [PubMed: 10662842]

50. Hackett TA, Barkat TR, O'Brien BM, et al. Linking topography to tonotopy in the mouse auditory thalamocortical circuit. J Neurosci. 2011; 31:2983-2995. [PubMed: 21414920]

51. Llinas RR, Leznik E, Urbano FJ. Temporal binding via cortical coincidence detection of specific and nonspecific thalamocortical inputs: a voltage-dependent dye-imaging study in mouse brain slices. Proc Natl Acad Sci U S A. 2002; 99:449-454. [PubMed: 11773628]

52. Beierlein M, Fall CP, Rinzel J, Yuste R. Thalamocortical bursts trigger recurrent activity in neocortical networks: layer 4 as a frequency-dependent gate. J Neurosci. 2002:9885-9894. J Neurosci. [PubMed: 12427845]

53. Kubota M, Sugimoto S, Horikawa J, et al. Optical imaging of dynamic horizontal spread of excitation in rat auditory cortex slices. Neuosci Lett. 1997; 237:77-80.

54. Kubota M, Nasu M, Taniguchi I. Layer-specific horizontal propagation of excitation in the auditory cortex. Neuroreport. 1999; 10:2865-2867. [PubMed: 10511454]

55. Broicher T, Bidmon HJ, Kamuf B, et al. Thalamic afferent activation of supragranular layers in auditory cortex in vitro: a voltage sensitive dye study. Neuroscience. 2010; 165:371-385. [PubMed: 19840834]

56. Kaur S, Rose HJ, Lazar R, et al. Spectral integration in primary auditory cortex: laminar processing of afferent input, in vivo and in vitro. Neuroscience. 2005; 134:1033-1045. [PubMed: 15979241]

57. Contreras D, Llinas R. Voltage-sensitive dye imaging of neocortical spatiotemporal dynamics to afferent activation frequency. J Neurosci. 2001; 21:9403-9413. [PubMed: 11717373]

58. Barbour DL, Callaway EM. Excitatory local connections of superficial neurons in rat auditory cortex. J Neurosci. 2008; 28:11174-11185. [PubMed: 18971460]

59. Llano DA, Sherman SM. Differences in intrinsic properties and local network connectivity of identified layer 5 and layer 6 adult mouse auditory corticothalamic neurons support a dual corticothalamic projection hypothesis. Cereb Cortex. 2009; 2009:2810-2826. [PubMed: 19351905]

60. Hooks BM, Hires SA, Zhang YX, et al. Laminar analysis of excitatory local circuits in vibrissal motor and sensory cortical areas. PLoS Biol. 2011; 9:e1000572. [PubMed: 21245906]

61. Zarrinpar A, Callaway EM. Local connections to specific types of layer 6 neurons in the rat visual cortex. J Neurophysiol. 2006; 95:1751-1761. [PubMed: 16319201]

62. Yoshimura Y, Dantzker JL, Callaway EM. Excitatory cortical neurons form fine-scale functional networks. Nature. 2005; 433:868-873. [PubMed: 15729343]

63. Briggs F, Callaway EM. Layer-specific input to distinct cell types in layer 6 of monkey primary visual cortex. J Neurosci. 2001; 15:3600-3608. [PubMed: 11331389]

64. Shepherd GM, Stepanyants A, Bureau I, et al. Geometric and functional organization of cortical circuits. Nat Neurosci. 2005; 8:782-790. [PubMed: 15880111]

65. Shepherd GM, Pologruto TA, Svoboda K. Circuit analysis of experience-dependent plasticity in the developing rat barrel cortex. Neuron. 2003; 38:277-289. [PubMed: 12718861]

66. Ojima H, Honda CN, Jones EG. Patterns of axon collateralization of identified supragranular pyramidal neurons in the cat auditory cortex. Cereb Cortex. 1991; 1:80-94. [PubMed: 1822727]

67. Ojima H, Honda CN, Jones EG. Characteristics of intracellularly injected infragranular pyramidal neurons in cat primary auditory cortex. Cereb Cortex. 1992; 2:197-216. [PubMed: 1511221]

68. Winer JA. Anatomy of layer IV in cat primary auditory cortex (AI). J Comp Neurol. 1984; 224:535-567. [PubMed: 6725630]

69. Winer JA. The non-pyramidal neurons in layer III of cat primary auditory cortex (AI). J Comp Neurol. 1984; 229:512-530. [PubMed: 6501610]

70. Winer JA. The pyramidal cells in layer III of cat primary auditory cortex. J Comp Neurol. 1984; 229:476-496. [PubMed: 6209308]

71. Prieto JJ, Winer JA. Layer VI in cat primary auditory cortex: Golgi study and sublaminar origins of projection neurons. J Comp Neurol. 1999; 404

72. Winer JA, Miller LM, Lee CC, Schreiner CE. Auditory thalamocortical transformation: structure and function. Trends Neurosci. 2005; 28:255-263. [PubMed: 15866200] 
73. Miller LM, Escabí MA, Read HL, Schreiner CE. Functional convergence of response properties in the auditory thalamocortical system. Neuron. 2001; 32:151-160. [PubMed: 11604146]

74. Lee CC, Winer JA. Connections of cat auditory cortex: I. Thalamocortical system. J Comp Neurol. 2008; 507:1879-1900. [PubMed: 18271026]

75. Scannell JW, Blakemore C, Young MP. Analysis of connectivity in the cat cerebral cortex. J Neurosci. 1995; 15:1463-1483. [PubMed: 7869111]

76. Bruno RM, Sakmann B. Cortex is driven by weak but synchronously active thalamocortical synapses. Science. 2006; 312:1622-1627. [PubMed: 16778049]

77. Douglas RJ, Koch C, Mahowald M, et al. Recurrent excitation in neocortical circuits. Science. 1995; 269:981-985. [PubMed: 7638624]

78. Ben-Yishai R, Bar-Or RL, Sompolinsky H. Theory of orientation tuning in visual cortex. Proc Natl Acad Sci U S A. 1995; 92:3844-3848. [PubMed: 7731993]

79. Liu BH, Wu GK, Arbuckle R, et al. Defining cortical frequency tuning with recurrent excitatory circuitry. Nat Neurosci. 2007; 10:1594-1600. [PubMed: 17994013]

80. MacLean JN, Watson BO, Aaron GB, Yuste R. Internal dynamics determine the cortical response to thalamic stimulation. Neuron. 2005; 8:811-823. [PubMed: 16337918]

81. Stoelzel CR, Bereshpolova Y, Gusev AG, Swadlow HA. The impact of an LGNd impulse on the awak visual cortex: synaptic dynamics and the sustained/transient distinction. J Neurosci. 2008; 28:5018-5028. [PubMed: 18463255] 

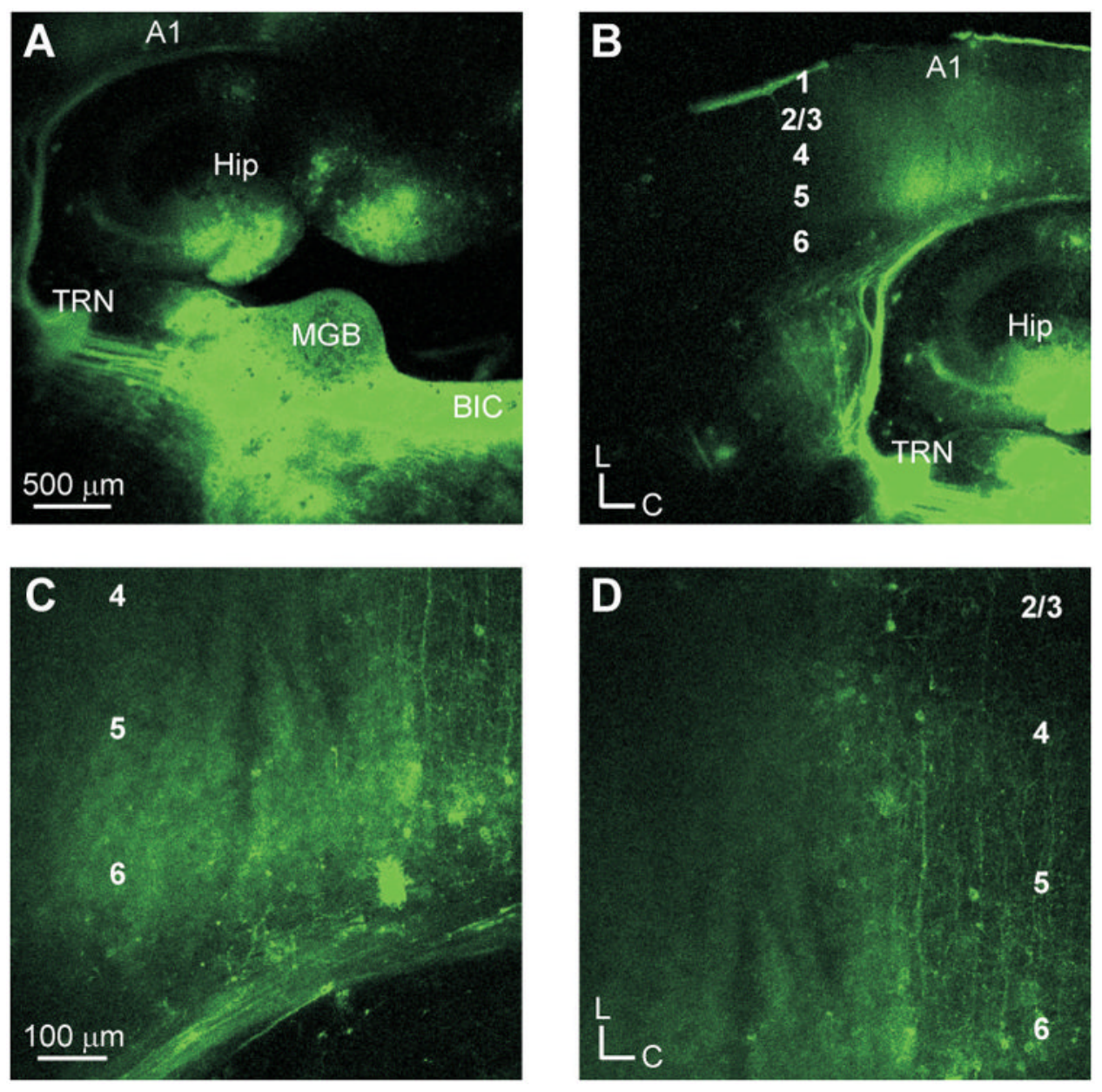

Fig. 1.

Thalamocortical projections in the auditory slice preparation. (A) Placement of DiI crystals in the medial geniculate body (MGB). Labeled fibers traverse toward the thalamic reticular nucleus (TRN) continuing onward towards the primary auditory cortex (A1). (B)

Thalamocortical fiber terminations in A1. (C) Labeled axonal fibers and retrogradely labeled cells in layer 6. (D) Labeled fibers extending to layer 4. 

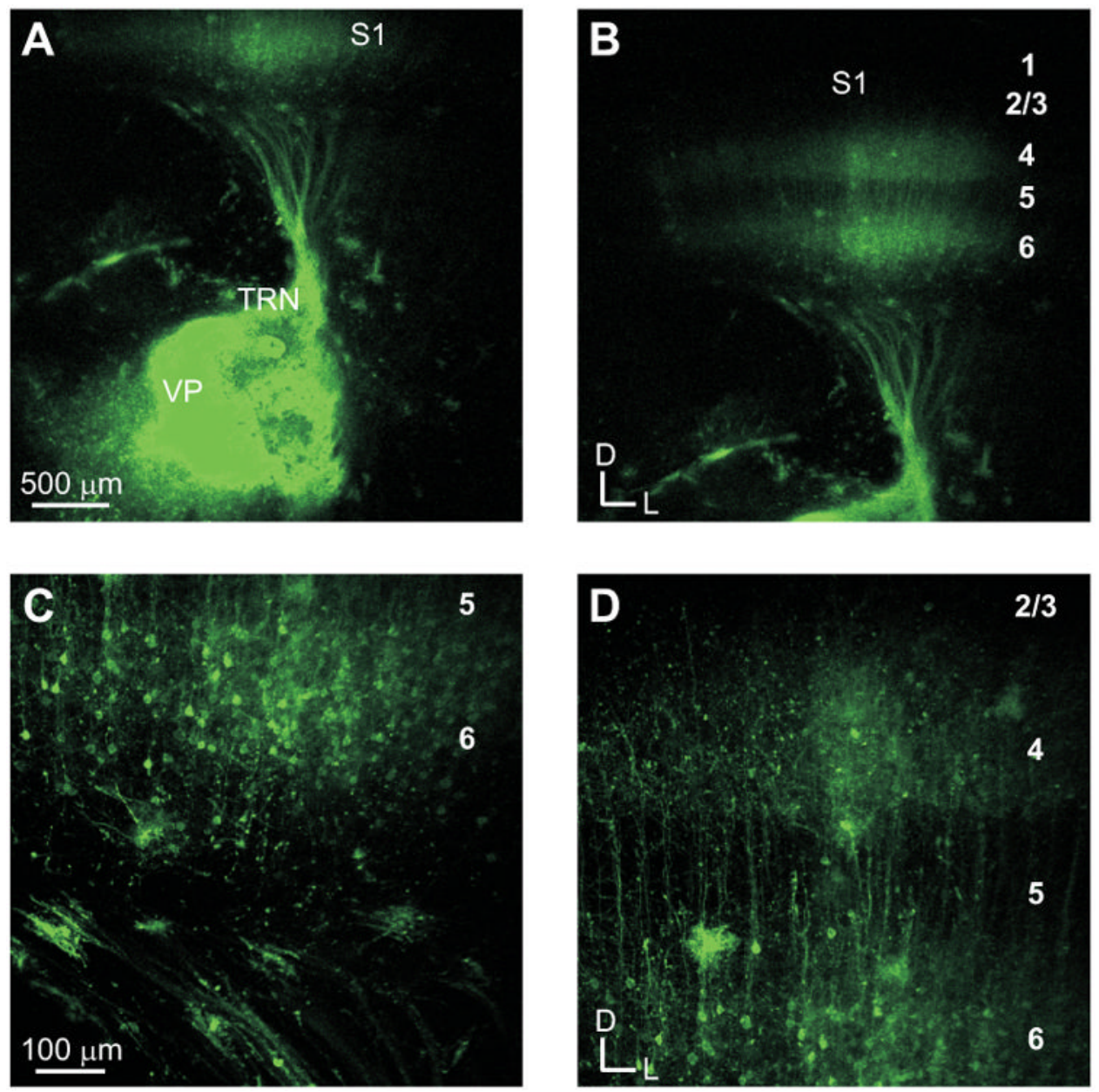

Fig. 2.

DiI tracing of projections in the somatosensory thalamocortical slice. (A) DiI crystal placement in the ventroposterior nucleus (VP) and fibers traversing to the primary somatosensory cortex (S1). (B) Fiber terminations in the primary somatosensory cortex. (C) Axonal fibers and retrogradely labeled cells in layer 6. (D) Labeled fibers extending to layer 4. 

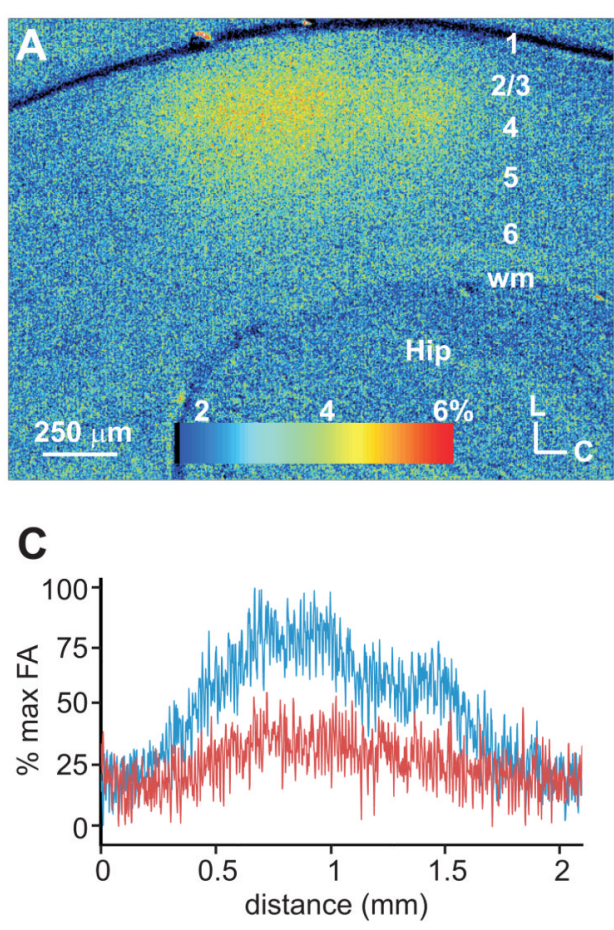

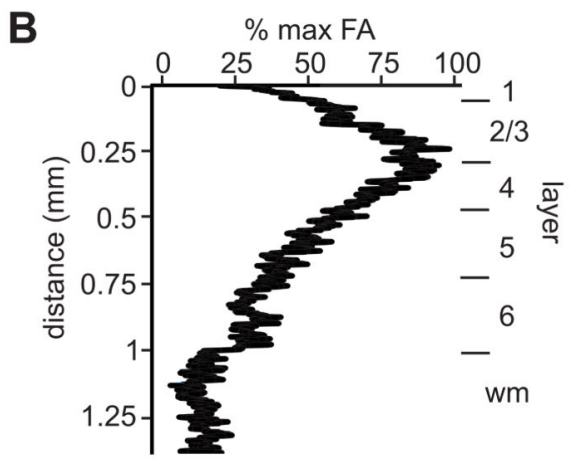

D

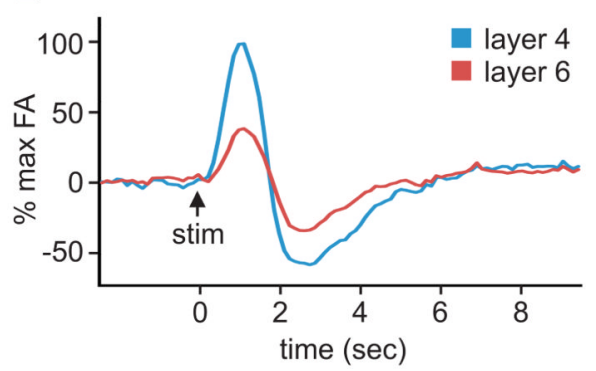

Fig. 3.

Areal and laminar activation pattern of flavoprotein autofluorescence (FA) in auditory cortex (A1) following electrical stimulation of the MGB. (A) FA image of A1 at the time of maximal autofluorescence following thalamic stimulation. (B) Laminar FA profile in A1 at the time of maximal autofluorescence. (C) Areal profile of FA responses across layers 4 and 6. (D) Time course of cortical FA response in layers 4 and 6 of A1. 

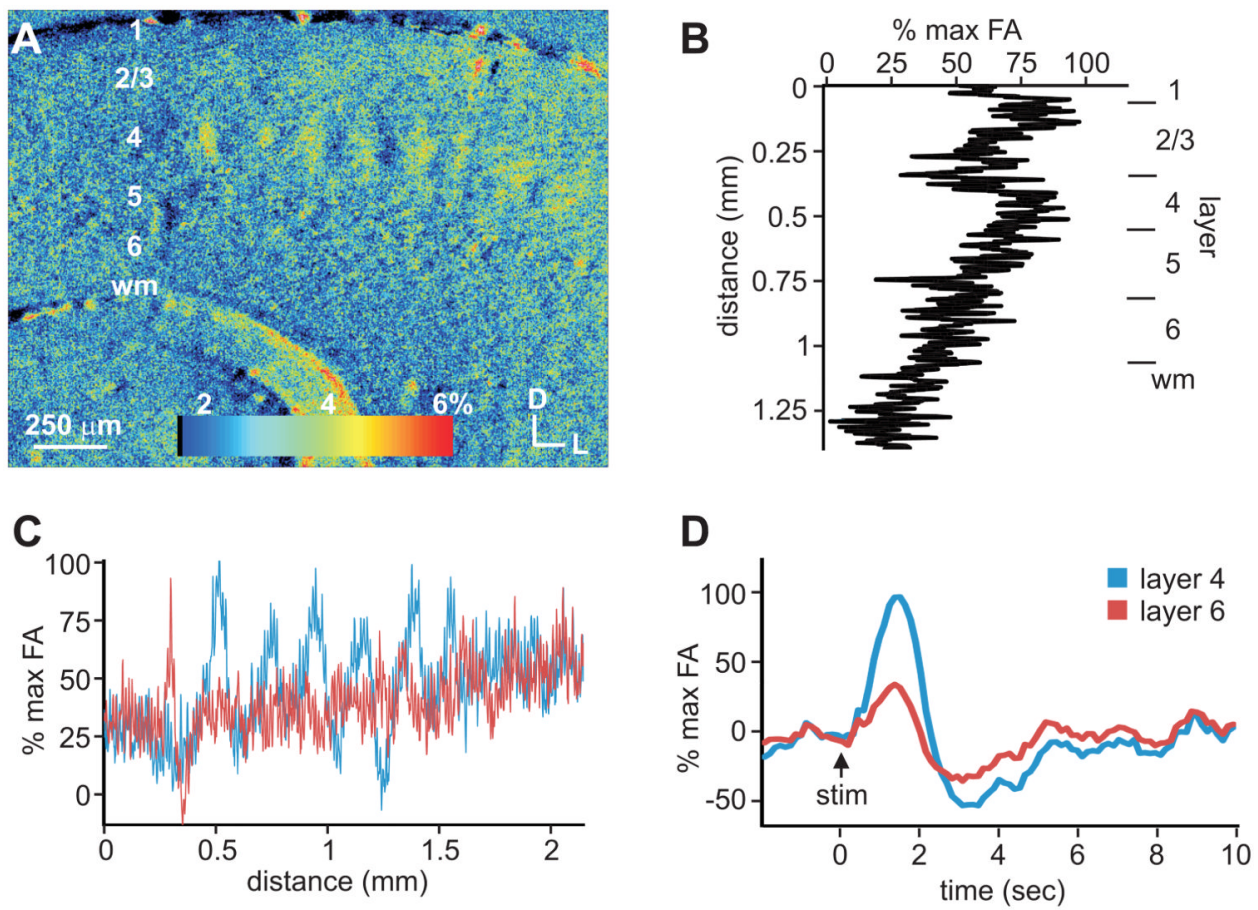

Fig. 4.

Areal and laminar activation pattern of flavoprotein autofluorescence (FA) in somatosensory cortex (S1) following electrical stimulation of VPm. (A) FA image of S1 at time of maximal autofluorescence following thalamic stimulation. (B) Autofluorescence responses across layers at time of maximal FA response. (C) Areal profile of FA responses across layers 4 and 6 in S1. (D) Time course of cortical FA response in layers 4 and 6 of S1. 

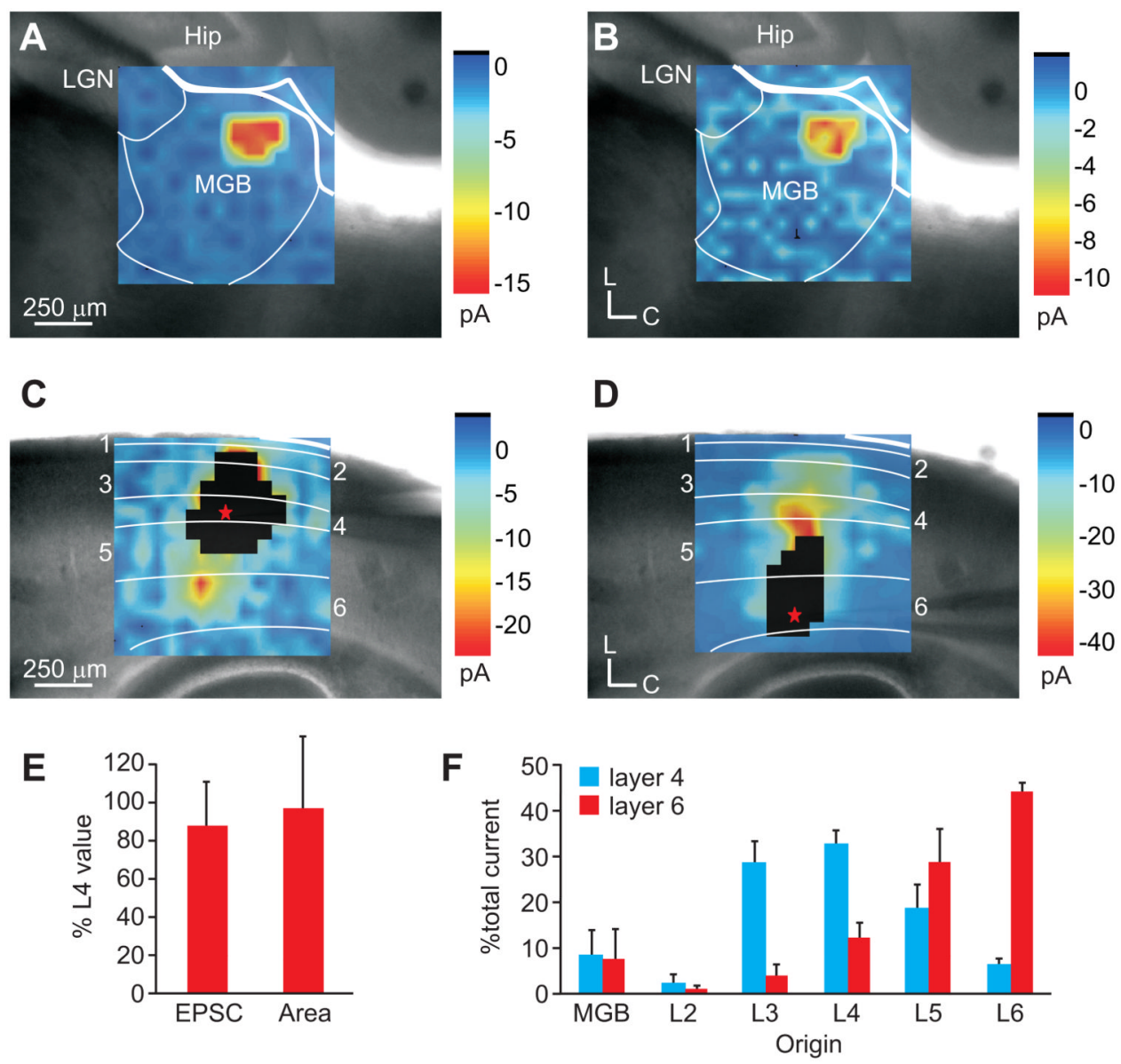

Fig. 5.

Auditory thalamocortical and intracortical inputs to layers 4 and 6 of A1. (A-D) Average LSPS plots of mean EPSCs recorded in a layer 4 neuron $(A, C)$ or a layer 6 neuron $(B, D)$ in response to photostimulation of the medial geniculate body (MGB; A-B) or auditory cortex (A1; C-D). White boxed regions in $C$ and $D$ illustrate direct response areas of recorded neurons. (E) Mean thalamic area and mean total evoked current in layer 6 normalized to that of layer 4 neurons recorded in the same column. (F) Mean percent of total current elicited from the MGB and layers 2-6 in either the layer 4 neuron (black) or layer 6 neuron (grey). 

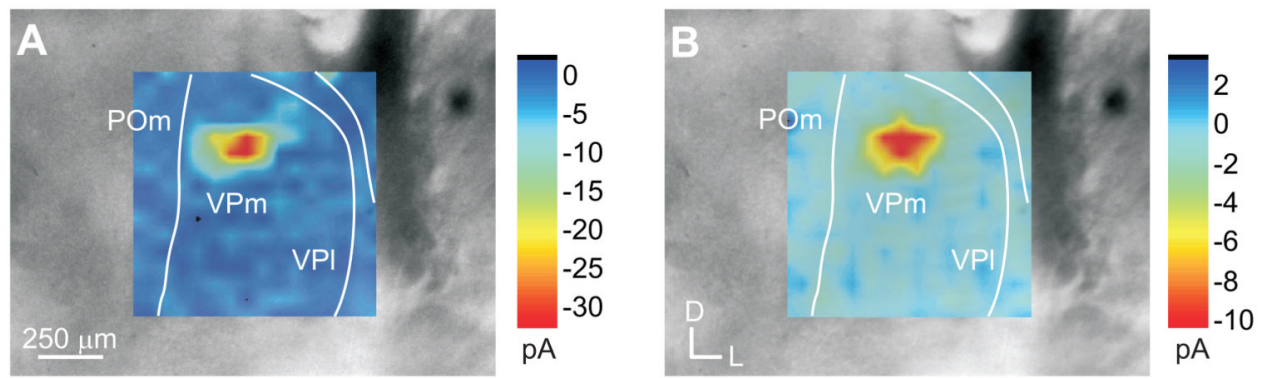

\section{C}
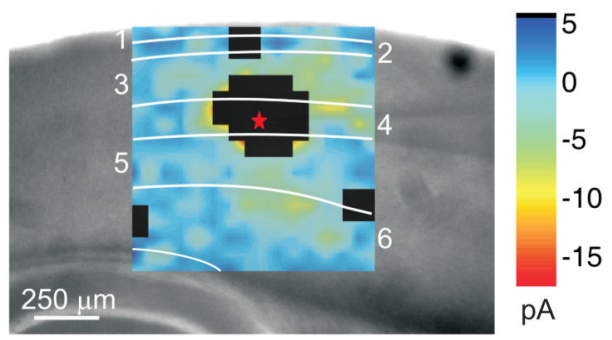

D
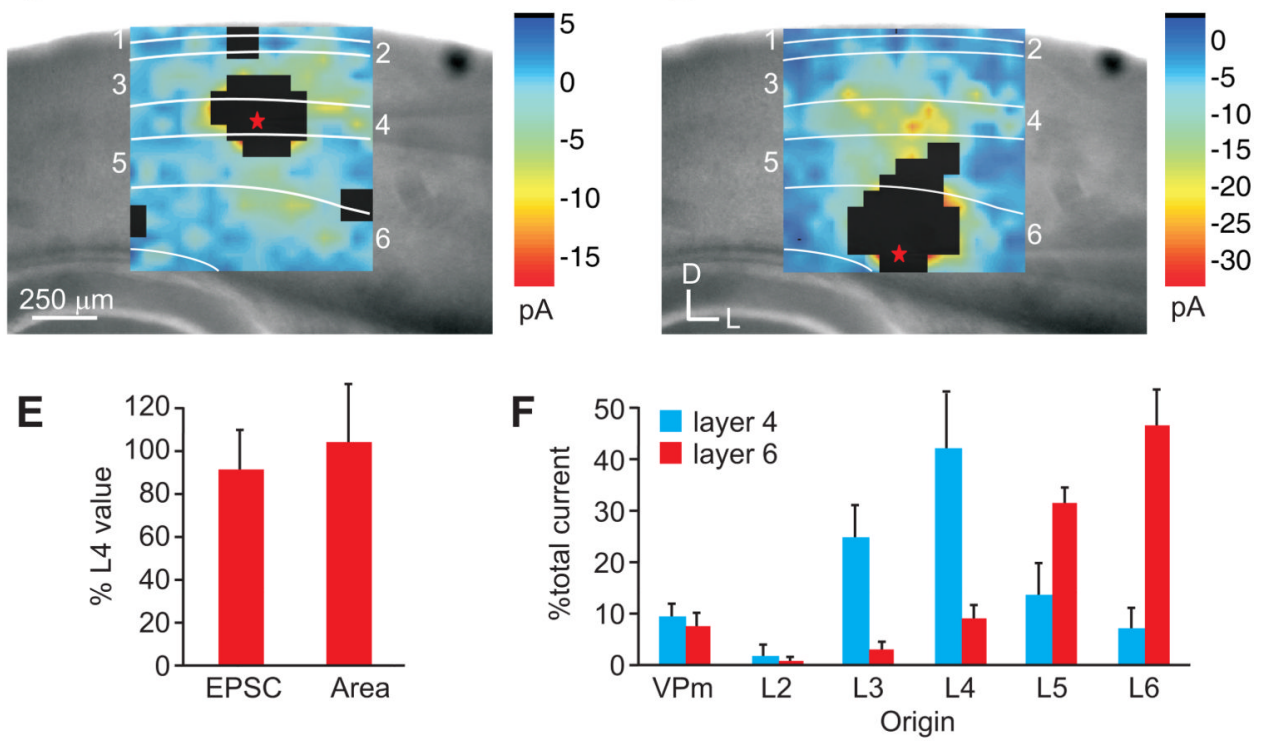

Fig. 6.

Somatosensory thalamocortical and intracortical inputs to layers 4 and 6 of S1. (A-D) Photostimulation of the ventralposterior medial nucleus (VPm; A-B) or primary somatosensory barrel cortex (SI; C-D). Plots illustrate averaged mean EPSCs. White boxed regions in $C$ and $D$ illustrate direct response areas of recorded neurons (E) Mean area evoking EPSCs in the thalamus and the mean total evoked current from VPm in layer 6 normalized to that of layer 4. (F) Mean percent of total current elicited from VPm and layers 2-6 in either the layer 4 neuron (black) or the layer 6 neuron (grey). 


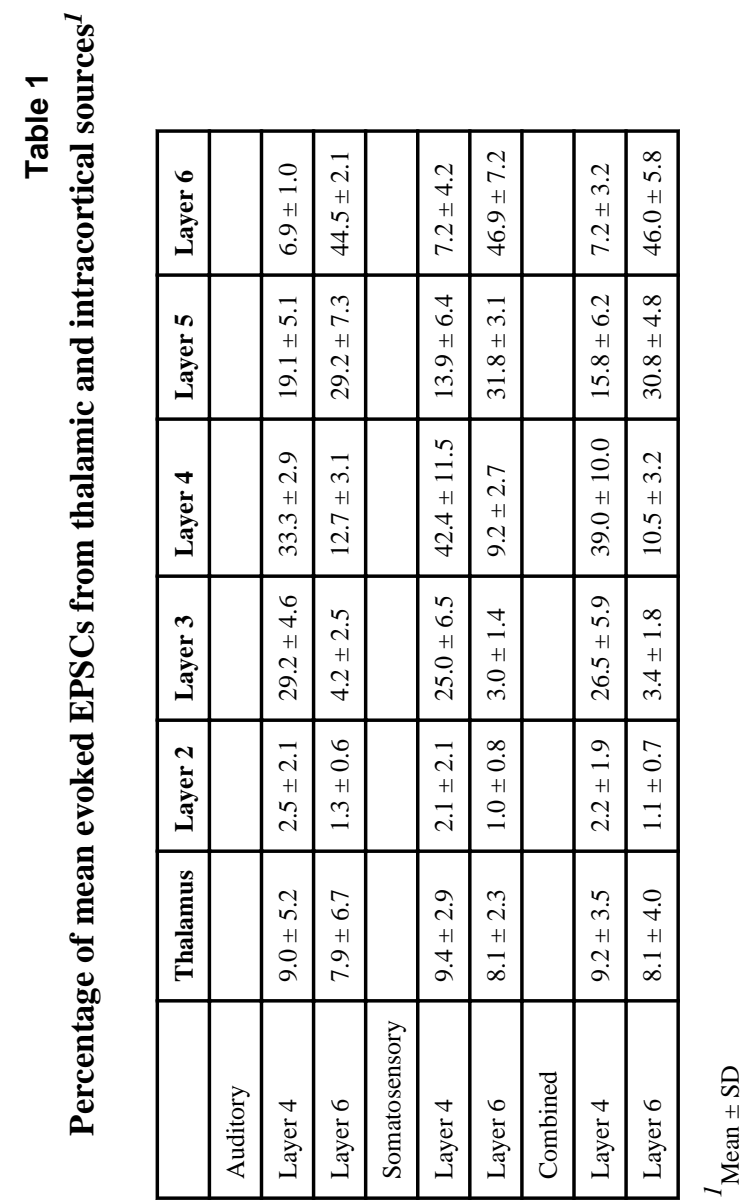

Neurophysiology. Author manuscript; available in PMC 2014 November 01. 